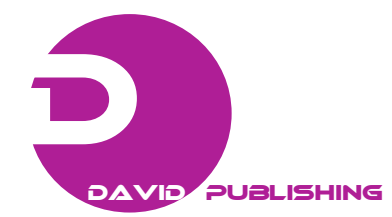

\title{
Analysis of the Modes of Vibration and Static Resistance of the Frame of a Stirred Tank
}

\author{
David Yemboini Kader Toguyeni, Stanislas Sanfo and Fati Zoma \\ Laboratory of Physics and Chemistry of the Environment (ECPA), University of Ouagadougou, Ouagadougou 03 BP 7021, Burkina \\ Faso
}

Received: August 12, 2013 / Accepted: October 10, 2013 / Published: January 31, 2014.

\begin{abstract}
The present study focuses on the design and choice of materials (steels S355 and 45SCD6) of a chassis of stirred tank (with a variable filling rate) for use in the manufacturing of cosmetic products. This tank or trough will be submitted to important mechanical and thermal loads and pressure according to the various manufacturing processes. The authors propose a model of thermal and mechanical loads which takes into account the operating conditions of the tank. The analysis of the first 10 modes of vibration of the frame shows that the frequencies are much higher when the filling rate is high. They are higher for steel 45SCD6 than for the S355. The simulation results show that for a selected type of steel, the equivalent Von Mises stress increases along with increase in fill rates and thermal gradient. It appears that the influence of the thermal gradient is predominant. For both steels, the Von Mises equivalent stress is maximum in the beam 32 when the thermal gradient is at its lowest stage, and in the beam 40 for the greatest thermal gradient.
\end{abstract}

Key words: Static strength, vibrations, chassis, stirred tank, buckling of beams.

\section{Introduction}

In a perspective of sustainable development and poverty reduction, emerging countries must ensure the local processing of their raw materials. Local processing is known to be likely to create more value and wealth.

Thus, in sub-Saharan Africa, particularly in West Africa a promotion of the extraction of shea butter from nuts is carried out for export or to be used as input in the manufacturing of soaps or emulsions for cosmetic products that are very much consumed by the population.

Therefore, the birth of small processing units that produce butter locally have been witnessed, by ensuring them a long life.

For their design, people should mainly be concerned with saving money and ensuring a better aesthetic presentation as well as operating in the safest possible

Corresponding author: Toguyeni David Yemboini Kader, Ph.D., research fields: materials and energy efficiency. E-mail: togyen@yahoo.fr or togyen@univ-ouaga.bf. conditions.

During the design phase, it is of utmost importance to identify potential problems in vibration design in order to prevent these problems [1]. This can be achieved by determining the natural frequencies of the structures by using a finite element analysis.

The task entrusted to us, was to propose a manufacturing unit for body care creams made of shea butter. A draft project is designed, in which a stirred tank used for the manufacturing of the emulsions is mounted on a steel frame; the manufacturing process is controlled from a control cabinet, with a circulation of hot or cold water in the jacket of the tank and this by using two pumps (Fig. 1).

The present work focuses on the "a priori" analysis of the performance of the frame on which the stirred tank is mounted, in terms of static and dynamic resistance [2-4] to mechanical and thermal stress imposed by production.

Specifically, people want to ensure that because of the building material used for the chassis (steel S355 or 
steel 45SCD6), no beam is going to burn, break or get the phenomenon of mechanical resonance.

The frame is then modeled in a fixed spatial network with 46 nodes and 64 rigid beams. Through the quality of the welding required, links are assumed to be rigid-rigid. The mechanical actions effected on the tank, the electric motor and the pumps are modeled by a point torque applied to the structure. The action of the control box on the frame is modeled by a uniformly distributed torque. Temperature gradients are applied to the beams which are in contact with the container or which are in its immediate environment. Indeed the temperature inside the tank must be increased from room temperature to $80^{\circ} \mathrm{C}$ for about $35 \mathrm{~min}$, and then lowered to that of the room for the production of emulsions. Numerical simulations are performed using the software RDM6 [5]. Analysis, both dynamic and static is taken into account in this work $[6,7]$.

\section{Methodological Approach}

The overall objective of the work is to study the dynamic and static behavior of the structure of the chassis under the effect of thermal and mechanical operating conditions of the tank.

The first specific objective is to study the vibration of the structure of the frame in order to make a judicious choice of pumps and electric motor for the mixer that would not attack the structure in one of its modes of vibration.

The second specific objective of the study is to establish that in the worst conditions of mechanical and thermal loading, the beams with larger values of Von Mises equivalent stress ( $\sigma_{V M}$ ) will not be damaged.

The network of bars welded together and on which the tank is set, the engine, both pumps and the control cabinet is shown in Figs. 2-4.

The RDM6 software used is version 6.16 of a series of integrated software (modules) for calculations of structures by the method of finite elements. The module used called "spatial structure" allows the study in 3 dimensions of the static and dynamic behavior of space frames.

\subsection{Assumptions of the Model and Equations}

The material of the beam is assumed to be homogeneous, isotropic, linear, thermo elastic. Deformation of the sections is taken into account (Timoshenko) or not (Bernoulli) $[3,8]$. Each beam is subject to the following equations:

- HOOKE's law of behaviour for linear thermo-elastic materials

$$
\begin{gathered}
\sigma=\frac{\mathrm{E}}{1+\boldsymbol{v}}\left(\boldsymbol{\varepsilon}+\frac{\boldsymbol{v}}{1-2 \boldsymbol{v}}(\operatorname{Trace} \boldsymbol{\varepsilon}) I\right) \\
-\frac{\mathrm{E}}{\mathbf{1}+\boldsymbol{v}} \boldsymbol{\alpha}\left(\mathrm{T}-\mathrm{T}_{\mathbf{0}}\right) I
\end{gathered}
$$

- Equation of the static

$$
\operatorname{div} \boldsymbol{\sigma}+f_{v}=\mathbf{0}
$$

Taken into account with the law of behaviour, the equation of the static leads to the Lamé-Navier equation below:

$$
\begin{gathered}
\frac{\mathrm{E}}{2(1+\boldsymbol{v})} \Delta u+\frac{\mathrm{E}}{2(1+\boldsymbol{v})(1-2 \boldsymbol{v})} \operatorname{grad}(\operatorname{divu}) \\
-\frac{\mathrm{E} \boldsymbol{\alpha}}{\mathbf{1 - 2 v}} \operatorname{grad}\left(\mathrm{T}-\mathrm{T}_{\mathbf{0}}\right)+f_{v}=\mathbf{0}
\end{gathered}
$$

- The equation of vibration of elastic materials

$$
\begin{gathered}
\frac{\mathrm{E}}{2(1+\boldsymbol{v})} \Delta u+\frac{\mathrm{E}}{2(1+\boldsymbol{v})(1-2 \boldsymbol{v})} \operatorname{grad}(\operatorname{div} u) \\
-\frac{\mathrm{E} \boldsymbol{\alpha}}{\mathbf{1 - 2} \boldsymbol{v}} \operatorname{grad}\left(\mathrm{T}-\mathrm{T}_{\mathbf{0}}\right)+f_{v}=\boldsymbol{\rho} \frac{\partial^{2} u}{\partial t^{2}}
\end{gathered}
$$

where, $v, E$ and u are Poisson's ratio, Young's modulus and the displacement.

In the context of the present work, their dependence on temperature is neglected unlike that of some authors [9] who had to cope with temperatures up to $950{ }^{\circ} \mathrm{C}$.

In addition to the assumptions given above, the following additional assumptions are made:

(1) The transverse shear is taken into account;

(2) The center of gravity and shear center of the right sections are merged.

\subsection{Modeling of Mechanical and Thermal Actions}

The specific weight of the beams and operating parts (tank, electric motors, pumps, control panels) is taken 


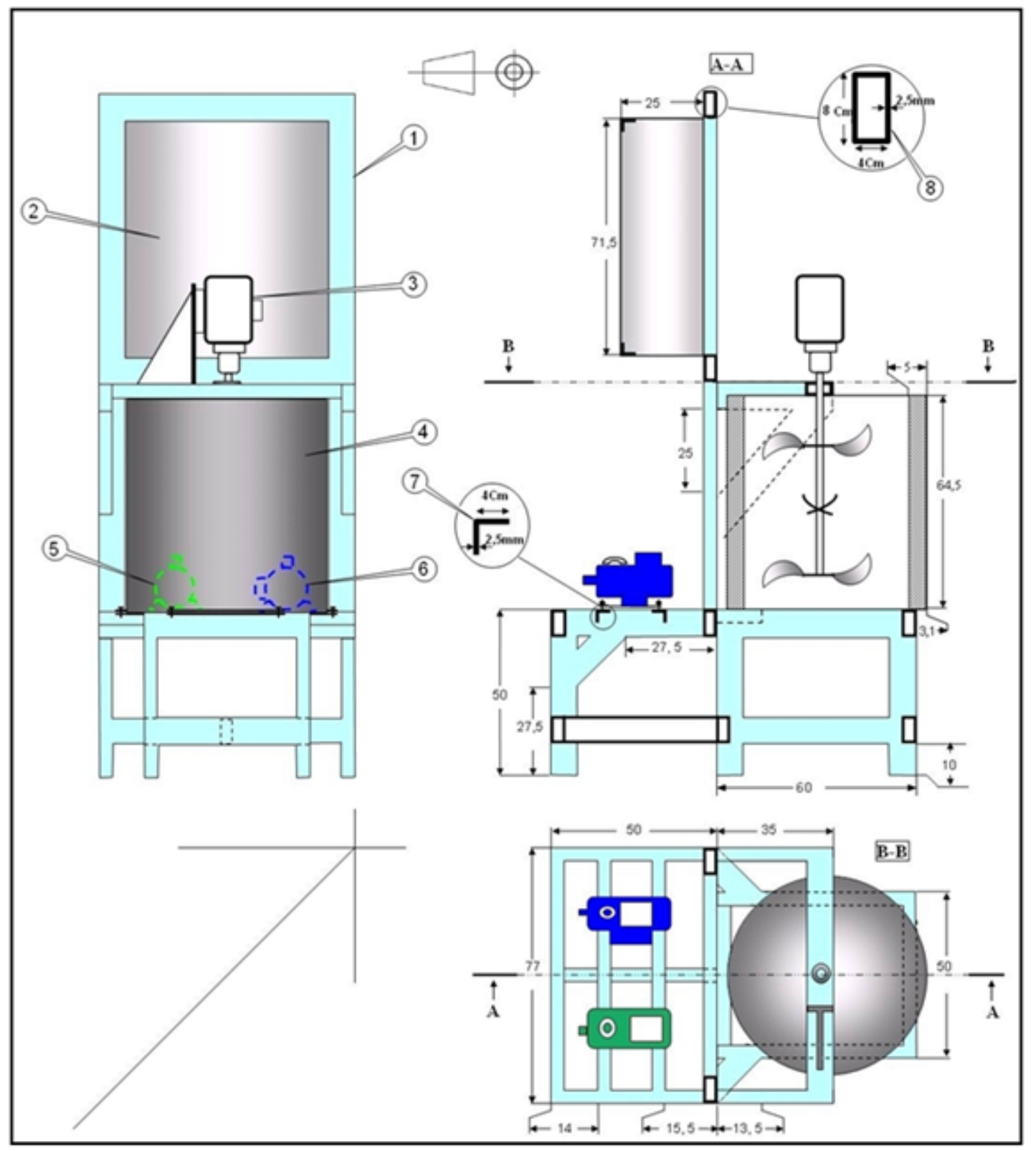

\begin{tabular}{|c|c|}
\hline (1): The frame & Length : L $=110 \mathrm{~cm}$, Height $: H=206 \mathrm{~cm} /$ Width $: l=77 \mathrm{~cm}$ \\
\hline $\begin{array}{l}\text { : The Cupboard } \\
\text { controls }\end{array}$ & $\begin{array}{l}\text { Weight : } 13 \mathrm{~kg} / \text { Height }: H=71.5 \mathrm{~cm} / \text { Length }: L=62 \mathrm{~cm} \\
\text { Width }: l=25 \mathrm{~cm}\end{array}$ \\
\hline $\begin{array}{l}\text { The electric } \\
\text { engine }\end{array}$ & $\begin{array}{l}\text { Weight : } 8 \mathrm{~kg} / \text { Power : } 1.5 \mathrm{~kW} \\
\text { Revolutions per minute : } N=1400 \mathrm{r} / \mathrm{min}\end{array}$ \\
\hline $\begin{array}{l}\text { : The cylindrical } \\
\text { tank }\end{array}$ & $\begin{array}{l}\text { Unladen weight : } 10 \mathrm{~kg} / \text { Heignt }: H=64.5 \mathrm{~cm} / \\
\text { External diameter }: \Phi_{c x t}=60 \mathrm{~cm} / \text { internal diameter }: \Phi_{\text {ist }}=50 \mathrm{~cm}\end{array}$ \\
\hline (5): The green pump & $\begin{array}{l}\text { Weight : } 3 \mathrm{~kg} / \text { Revolutions per minute }: N=2850 \mathrm{r} / \mathrm{min} \\
\text { Power : } 0.37 \mathrm{~kW}\end{array}$ \\
\hline : The blue pump & $\begin{array}{l}\text { Weight : } 0.6 \mathrm{~kg} / \text { Flow }: 26 \mathrm{l} / \mathrm{mn} / \text { Pressure }: P=2.5 \text { bar } \\
\text { Voltage: } V=12 \mathrm{Vcc} / \text { Amp }: I=2.5 \mathrm{~A} \\
\text { Revolutions per minute }: N=500 \mathrm{r} / \mathrm{min}\end{array}$ \\
\hline
\end{tabular}

Fig. 1 Cross sections of the production unit. 


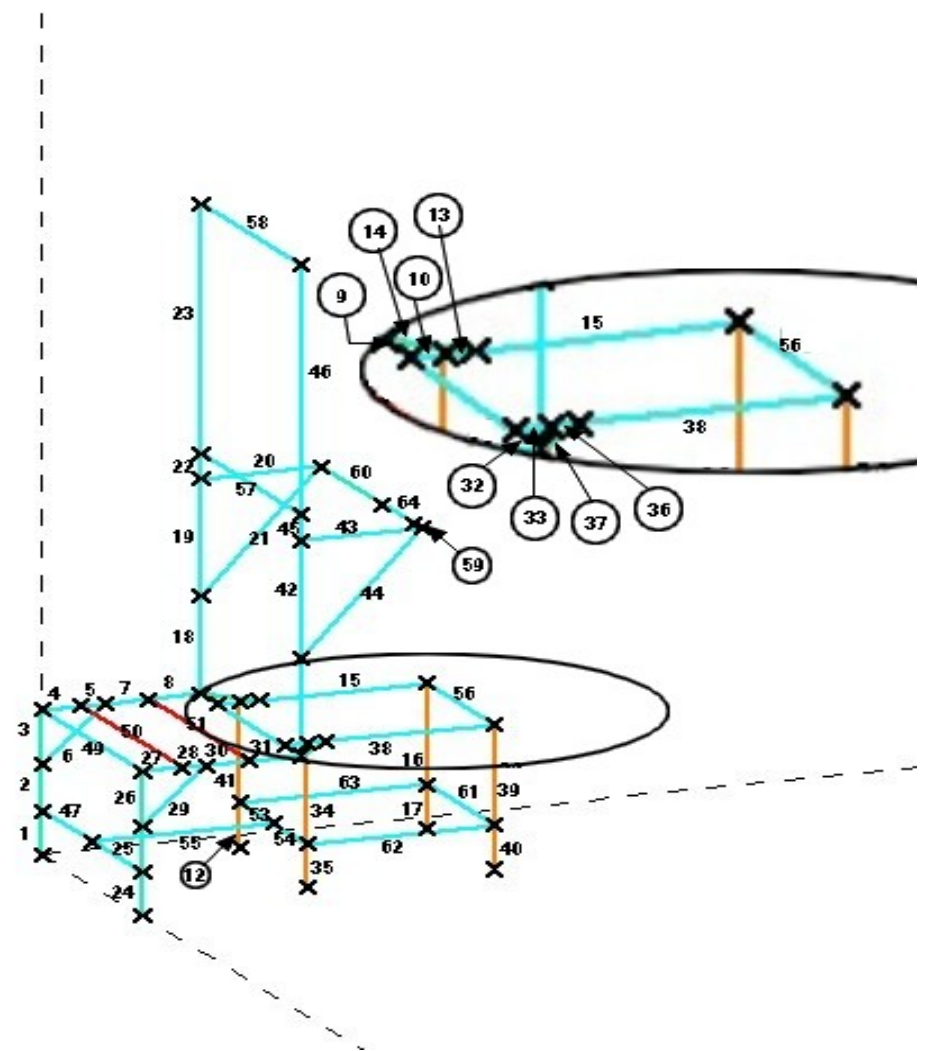

(a) Network of beams

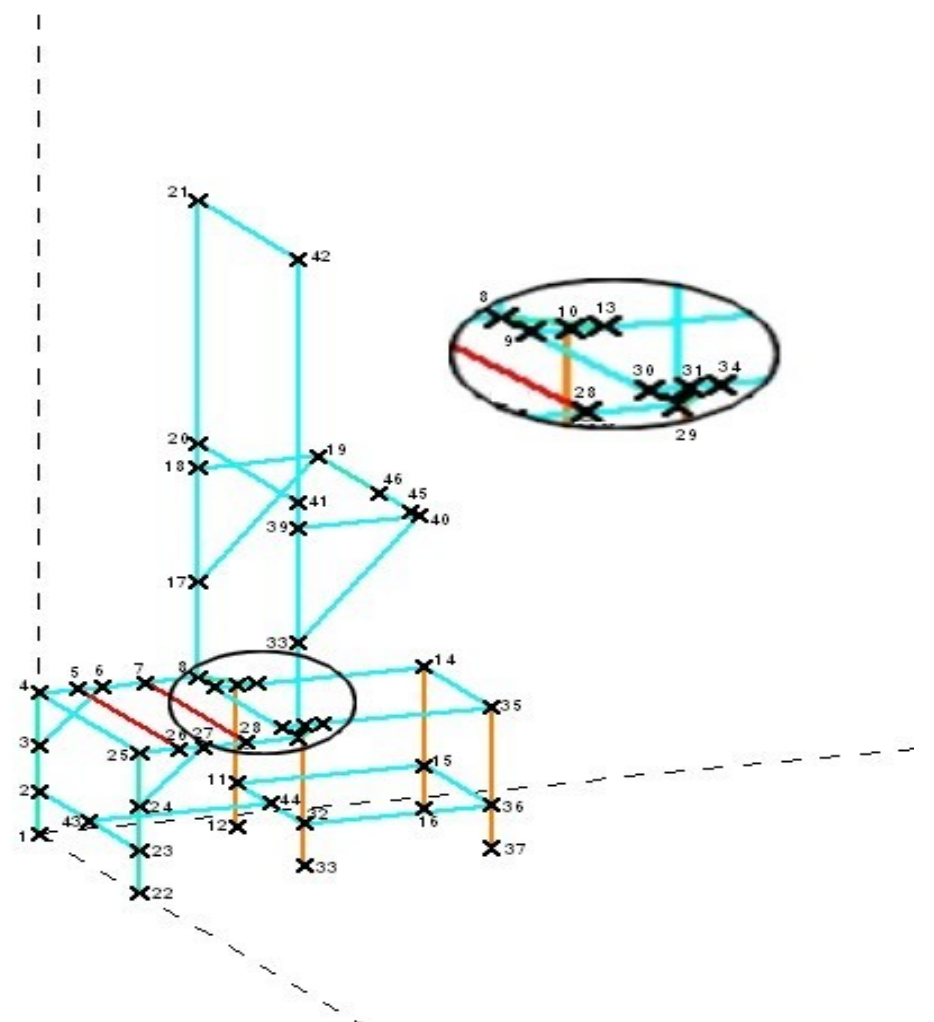

(b) The nodes

Fig. 2 (a) Network of beams and (b) the nodes. 


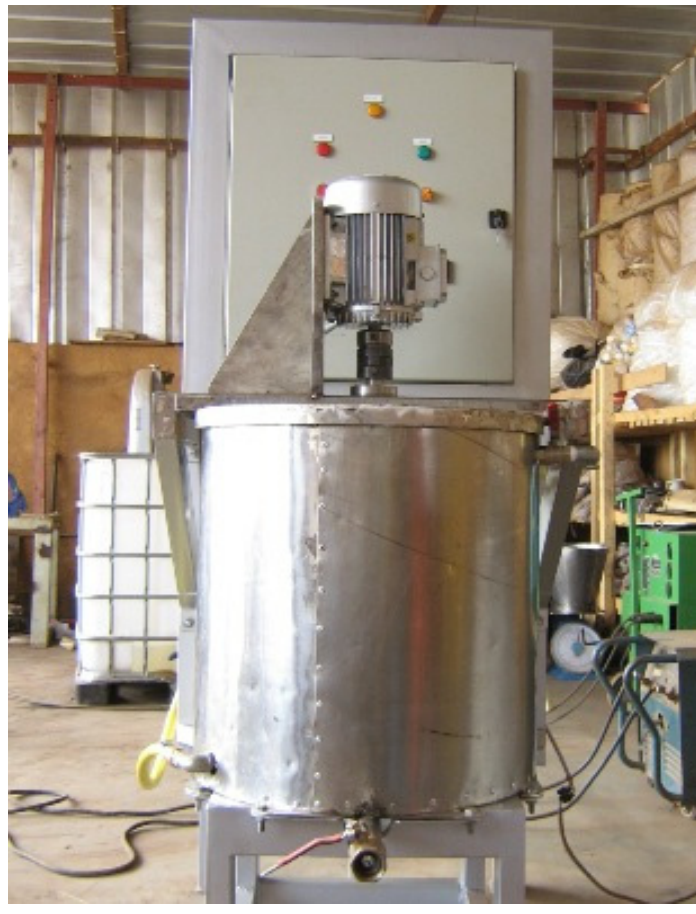

Fig. 3 The stirred tank bolted to the chassis.

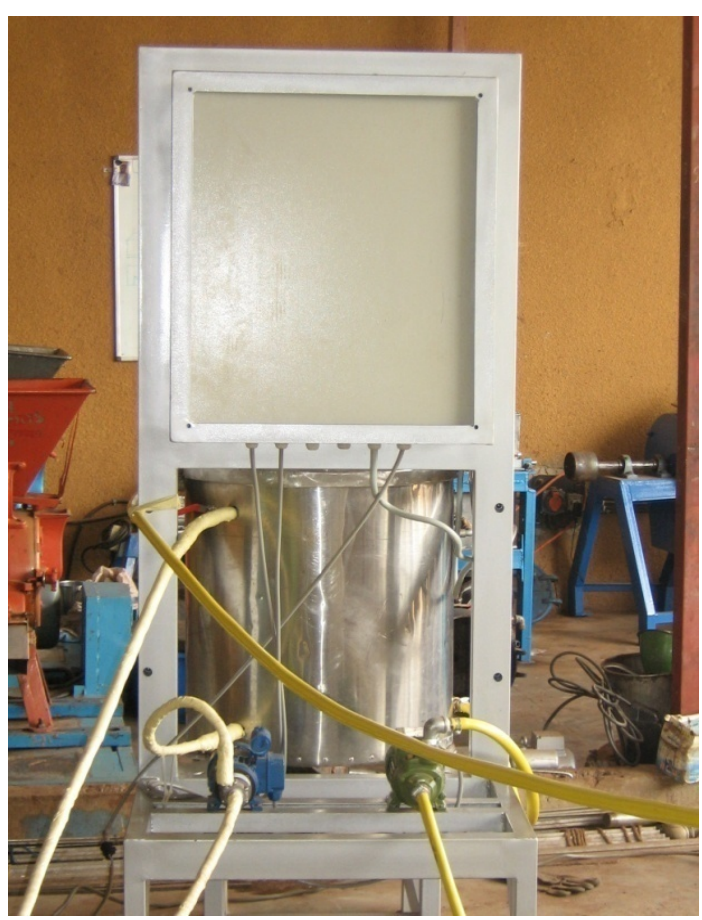

Fig. 4 Blue and green pumps.

into account. Beams numbered 1, 12, 17, 24, 35 and 36 are assumed fixed to the ground.

\subsubsection{The Stirred Tank}

During the procedure, the temperature of the tank is increased from room temperature to $80{ }^{\circ} \mathrm{C}$ to be maintained there for $30 \mathrm{~min}$ and then brought back to ambient temperature. The tank may be partially or completely filled with the cosmetic product. Beams $\mathrm{N}^{\circ} 15,38$ and 56 in contact with the tank, those numbered 59, 60 and 64 in contact with the lid of the tank or with the electric motor have a temperature gradient in relation to the ambient temperature due to the thermal transfer. Similarly, the beams $N^{\circ} 20,21,43$ and 44 which are in the immediate vicinity of the tank have a thermal gradient from about $3{ }^{\circ} \mathrm{C}$ to $5{ }^{\circ} \mathrm{C}$. The weight of the tank which depends on the filling rate is modeled by a uniform density of load on beams 15,38 and 56.

\subsubsection{The Electric Motor}

The weight of the engine is estimated at $80 \mathrm{~N}$, and given its angular velocity of rotation, it develops a torque of $10.23 \mathrm{~N} \cdot \mathrm{m}$. The mechanical action is equivalent to a torque:

$$
\left\{\begin{array}{l}
-80 N \vec{e}_{z} \\
10.23 N m \vec{e}_{x}
\end{array}\right\}
$$

\subsubsection{The Blue Pump}

Its mechanical action on the frame is equivalent to a force $-1.5 N \vec{e}_{z}$ applied at $11 \mathrm{~cm}, 19 \mathrm{~cm}$ and $-7.5 N \vec{e}_{z}$ at $48 \mathrm{~cm}$ and $58 \mathrm{~cm}$ starting from node $5 \mathrm{on}$ beam 50 and similarly on the beam 51 from node 7 .

\subsubsection{The Green Pump}

The mechanical action of the green pump on the frame is equivalent to a force $-3.6 N \vec{e}_{z}$ applied at 11 $\mathrm{cm}, 19 \mathrm{~cm}$ and $-6.2 N \vec{e}_{z}$ at $48 \mathrm{~cm}$ and $58 \mathrm{~cm}$ from node 5 beam 50 and similarly on beam 51 from node 7 .

2.2.5 The Controls Cabinet

Considering the way the controls cabinet is positioned on the chassis, mechanical actions are equivalent to a torque applied uniformly of $4.1 \mathrm{Nm} \vec{e}_{x}$ to the two nodes of beam 58 and a torque $\left\{\begin{array}{l}-65 N \vec{e}_{z} \\ 4.1 N m \vec{e}_{x}\end{array}\right\}$ to the nodes of beam 57 . The mechanical loads can be summarized in Table 1.

\subsection{The Simulation Parameters}

The simulation parameters are given below: 
Table 1 Modeling of mechanical and thermal loads.

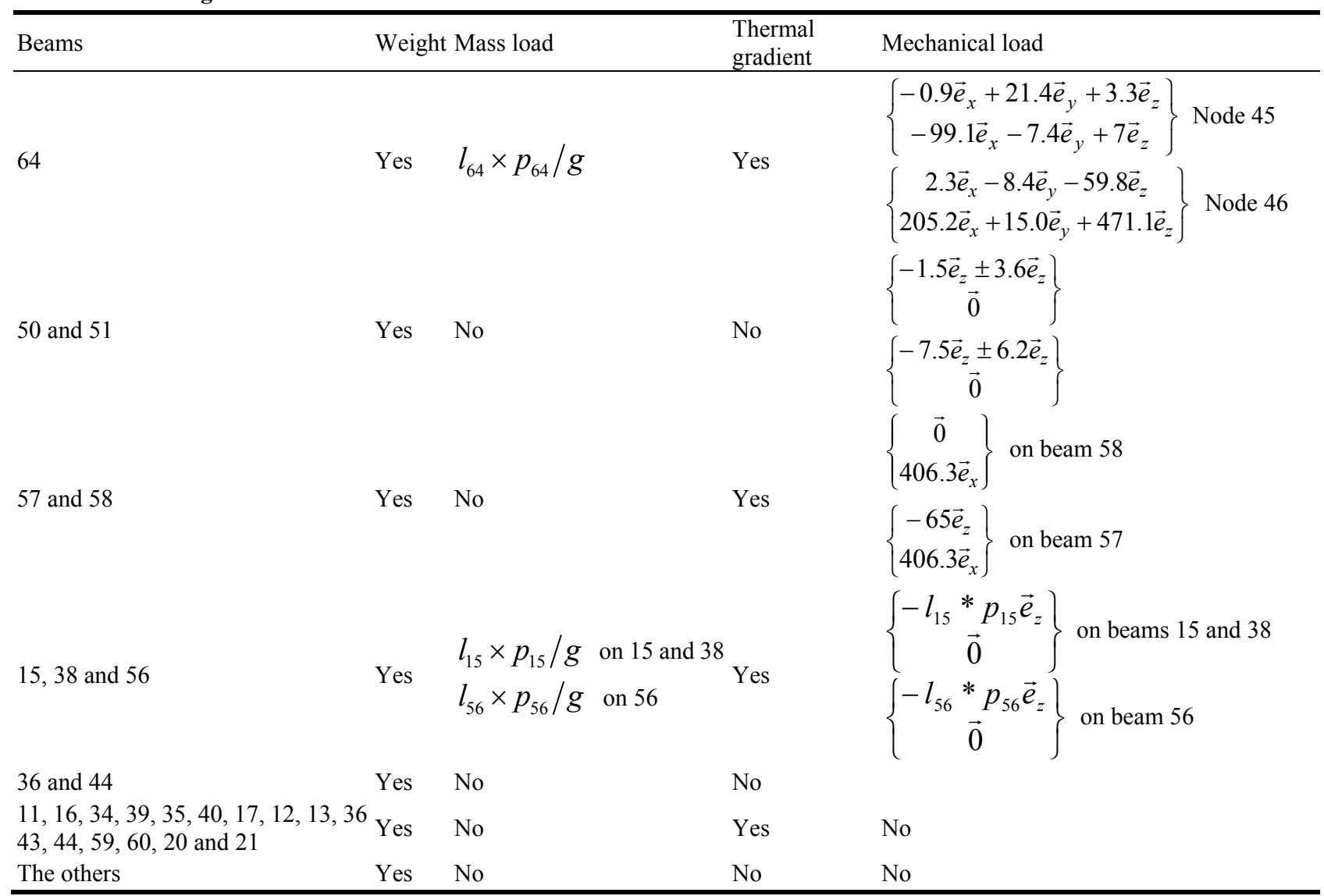

Table 2 Description of simulation cases.

\begin{tabular}{lllll}
\hline Test & $\begin{array}{l}\text { Type of } \\
\text { steel }\end{array}$ & $\begin{array}{l}\text { Fill rate of the } \\
\operatorname{tank}(\%)\end{array}$ & $\Delta T_{1}\left({ }^{\circ} \mathrm{C}\right)$ & $\Delta T_{2}\left({ }^{\circ} \mathrm{C}\right)$ \\
\hline 1 & 0 & 20 & \\
2 & 25 & 3 \\
3 & 50 & & \\
4 & 75 & & \\
5 & & 100 & 5 \\
6 & S335 & 0 & 30 & \\
7 & & 25 & \\
8 & & 50 & \\
9 & 75 & & \\
10 & & 100 & & \\
\hline 11 & & 0 & & \\
12 & & 25 & 30 & 5 \\
13 & $45 S C D 6$ & 50 & & \\
14 & & 100 & & \\
15 & & 0 & & \\
16 & & & & \\
\hline
\end{tabular}

- The fill factor $(\tau)$ of the tank are fixed to $0 \%, 25 \%$, $50 \%$ and $100 \%$;

- The type of frame material: steel S355 (mild steel, commonly used in Africa) or steel 45SCD6 (with a high elastic limit), whose mechanical properties are available in Refs. [7, 8, 10, 11];

- The temperature gradients over the beams 11,12 , $15,16,17,34,35,38,39,40,54,56,61,62$ and 63 .

Measurements taken during the stage of testing on units of production give the following thermal gradients:

- $\Delta T_{1}: 20{ }^{\circ} \mathrm{C}$ to $30{ }^{\circ} \mathrm{C}$ between the atmosphere and beams $15,38,56$;

- $\Delta T_{2}: 3{ }^{\circ} \mathrm{C}$ to $5^{\circ} \mathrm{C}$ between the atmosphere and beams 11, 12, 16, 17, 34, 35, 39, 40, 54, 61, 62, 63 .

For simulation purposes, the temperature gradients $\left(\Delta T_{1}, \Delta T_{2}\right)$ are set at $\left(20^{\circ} \mathrm{C}, 3^{\circ} \mathrm{C}\right)$ or $\left(30^{\circ} \mathrm{C}, 5^{\circ} \mathrm{C}\right)$.

To sum up, for each of the two types of steel, there are 10 cases of load to simulate.

\section{Simulation and Analysis of Results}

For the analysis of modes of vibration of the 
structure, in addition to the 10 test cases for each of the two types of steel, people study those of the unfilled frame made of steel 45SCD6 or S355. The results are given in Table 3 and Figs. 5 and 6.

The results of simulation on the first ten vibration modes show that:

(1) For a chosen type of material, the frequencies of vibration depend little on the rate of filling of the tank and retained realistic thermal gradients. If comparing the frequencies of vibration with those obtained for the unloaded chassis, people get relative differences ranging from $0.1 \%$ to $17 \%$.

(2) When a thermal gradient and a filling rate are set, the relative difference in the first 10 modes between the frequency values for the two types of steel is of the order of $3 \%$. This suggests that the choice of the type of steel is less important than the spatial distribution of the chassis beams for the determination of vibration modes.

For each of the 20 test cases, the beam or beams having the larger value of $\sigma_{V M}$ must be found. Assuming that the beams are deformable material whose Cauchy stress tensor has the following form in the basis of the principal directions: $\vec{X}, \vec{Y}$ and $\vec{Z}$ :

$$
\sigma(M)=\left[\begin{array}{ccc}
\sigma_{X} & 0 & 0 \\
0 & \sigma_{Y} & 0 \\
0 & 0 & \sigma_{Z}
\end{array}\right]_{(\vec{X}, \vec{Y}, \vec{Z})}
$$

Stress $\sigma_{V M}$ is defined by:

$$
\begin{gathered}
\sigma_{V M}=1 / \sqrt{2}\left(\left(\sigma_{X}-\sigma_{Y}\right)^{2}+\left(\sigma_{Y}-\sigma_{Z}\right)^{2}\right. \\
\left.\left.+\left(\sigma_{X}-\sigma_{Z}\right)^{2}\right)\right)^{0.5}
\end{gathered}
$$

Table 4 summarizes the results obtained for $\sigma_{V M}$.

The analysis of the stress within the frame shows that:

(1) Von Mises equivalent stresses are higher when the charge rate and thermal gradients get higher;

(2) Anyway, everything being equal, steel 45SCD6 lead to higher Von Mises equivalent stresses than the S355;

(3) For each type of steel, the maximum equivalent stress of Von Mises is at the embedding point of beam 32 when the thermal gradients apply $\left(\Delta T_{1}, \Delta T_{2}\right)=$ $\left(20^{\circ} \mathrm{C}, 3{ }^{\circ} \mathrm{C}\right)$. Conversely when $\left(\Delta T_{1}, \Delta T_{2}\right)=\left(30^{\circ} \mathrm{C}\right.$, $5{ }^{\circ} \mathrm{C}$ ), the maximum Von Mises stress is found at the embedding point of beam 40 .

Table 3 Fundamental Frequencies of the chassis according to imposed loads and steel.

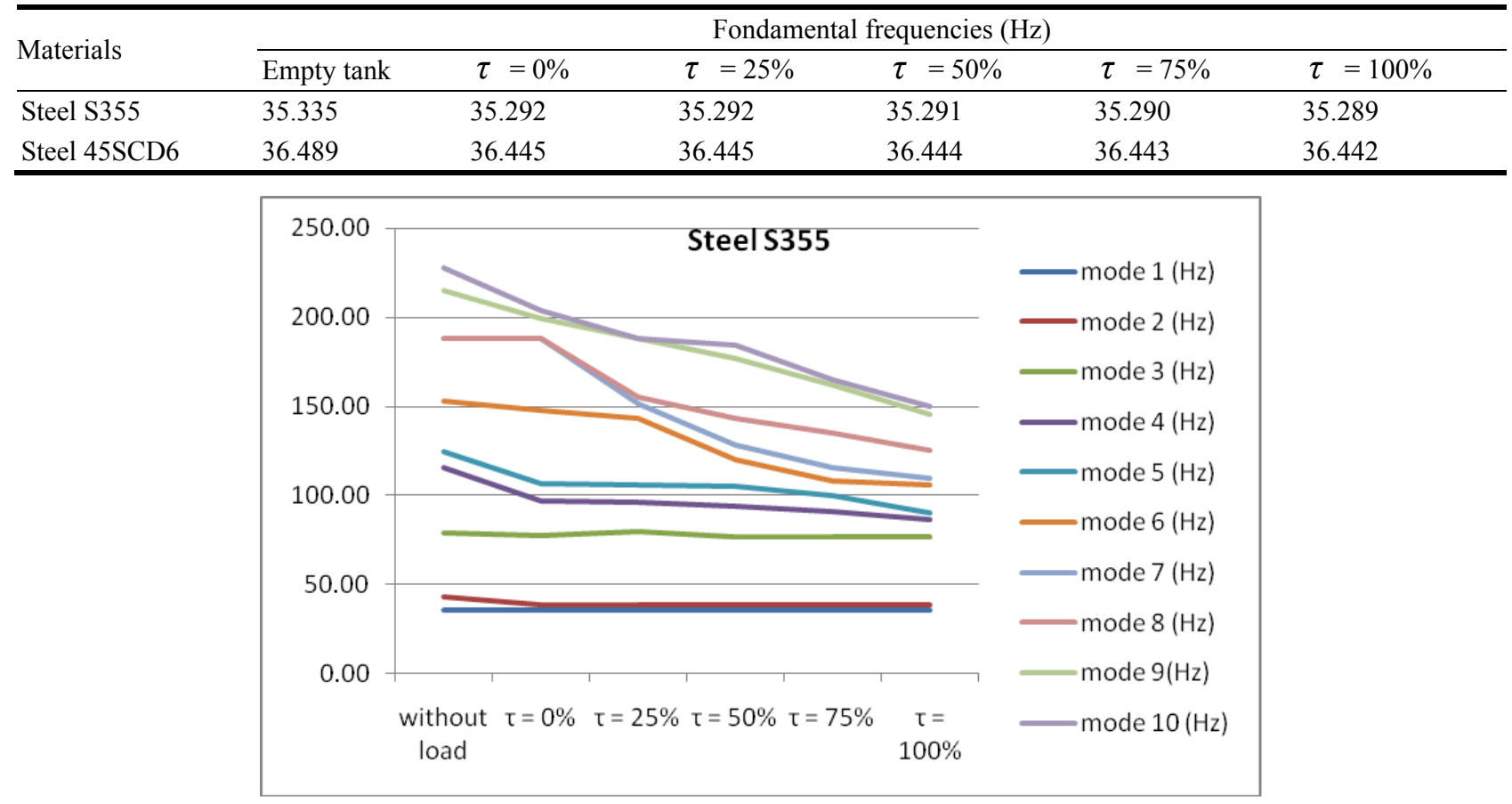

Fig. 5 The first 10 modes of vibration for steel S355. 


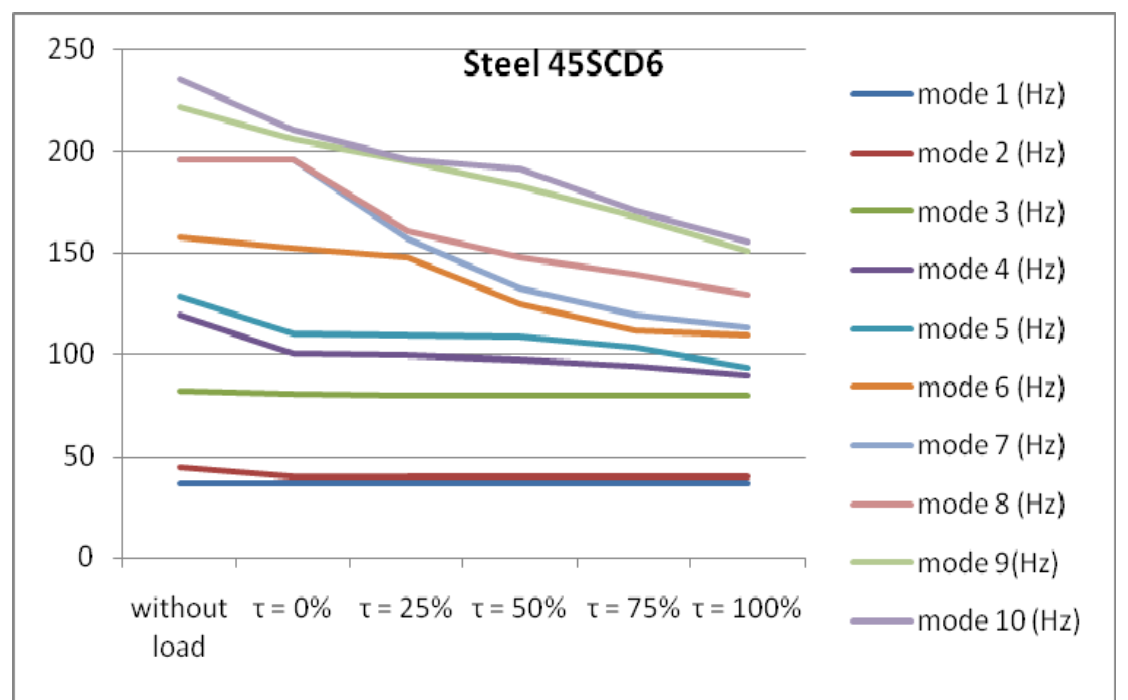

Fig. 6 The first 10 modes of vibration for steel 45SCD6.

Table 4 Von Mises equivalent stress and allowable stress $\left(\sigma_{e} / S\right) 2$.

\begin{tabular}{llllll}
\hline \multirow{2}{*}{ Materials } & \multicolumn{5}{c}{ Von Mises' equivalent stress (Mpa) } \\
\cline { 2 - 6 } & $\tau=0 \%$ & $\tau=25 \%$ & $\tau=50 \%$ & $\tau=75 \%$ & \multicolumn{1}{c}{$=100 \%$} \\
\hline Steel S355 & 28.83 & 28.96 & 29.09 & 29.2 & 29.34 \\
Steel 45SCD6 & 30.94 & 31.06 & 31.19 & 31.32 & 31.45 \\
$\boldsymbol{\sigma}_{e} / S(\mathrm{MPa})$ & 71 & 71 & 71 & 71 & 71 \\
\hline
\end{tabular}

Table 5 Minimum critical buckling ratio.

\begin{tabular}{|c|c|c|c|c|c|}
\hline \multirow{2}{*}{$\tau(\%)$} & \multicolumn{5}{|c|}{$\left(\Delta T_{1}, \Delta T_{2}\right)=\left(30^{\circ} \mathrm{C}, 5^{\circ} \mathrm{C}\right)$} \\
\hline & 0 & 25 & 50 & 75 & 100 \\
\hline $45 \mathrm{SCD} 6$ & $1,564.9$ & $1,566.1$ & $1,567.1$ & $1,567.7$ & $1,568.0$ \\
\hline S355 & $1,560.1$ & $1,561.5$ & $1,562.4$ & $1,563.1$ & $1,563.4$ \\
\hline
\end{tabular}

Table 6 Minimum critical buckling ratio.

\begin{tabular}{|c|c|c|c|c|c|}
\hline \multirow{2}{*}{$\tau(\%)$} & \multicolumn{5}{|c|}{$\left(\Delta T_{1}, \Delta T_{2}\right)=\left(20^{\circ} \mathrm{C}, 3^{\circ} \mathrm{C}\right)$} \\
\hline & 0 & 25 & 50 & 75 & 100 \\
\hline 45SCD6 & $2,402.3$ & $2,407.7$ & $2,405.7$ & $2,407.8$ & $2,380.6$ \\
\hline S355 & $2,392.9$ & $2,407.7$ & $2,396.0$ & $2,396.4$ & $2,366.5$ \\
\hline
\end{tabular}

In 10 test cases, it appears that beam 32 is subject to the highest stress, whereas for the other ten, it is beam 40. Thus, the strength of the frame depends on the loading conditions which must be examined. People must compare the Von Mises equivalent stress in beams 32 and 40 and the allowable stress which is the ratio between the elastic limit and safety factor $S$. Taking into account the quality of welding and steel types [12], people retain value 5 for $S$. According to Refs. $[8,9,10,13]$, the elastic limit is equal to $355 \mathrm{MPa}$. In the worst operating conditions, that is to say with a filling rate of $100 \%$ and maximum thermal gradients, and despite a high safety factor $(S=5)$, the Von Mises equivalent stress is not achieved in the beams 32 and 40.

A risk analysis of buckling (Tables 5 and 6) shows that:

(1) The minimum critical buckling coefficient is the same for steel S355 45SCD6 and whatever the load rate of the tank, when the thermal gradient pair $\left(\Delta T_{1}, \Delta T_{2}\right)$ is kept constant.

(2) The minimum critical buckling coefficient is 
much higher than the thermal loading is important.

\section{Conclusions}

This work highlights the difficulty of modeling a real problem and the effects of thermo-elastic coupling. The simulations show that the values of the Von Mises equivalent stress are mainly determined by the rate of filling of the tank, the value of the temperature gradient on the beams that are in the immediate vicinity of the tank, and the type of steel. It could be established that even in the worst conditions, the frame will not be damaged.

The work has permitted to identify potential vibration problems during the design stage. This can help in the choosing the pumps and the appropriate strategy for vibration damping, for example, by the use of vibration absorbers.

According to Table 3, the authors can suggest that the pumps frequencies should be less than $35 \mathrm{~Hz}$.

The authors can suggest for further studies to take in account forced vibrations due to pumps or electric motor and learn how to reduce vibration amplitude and thus prevent threshold and fatigue failures.

\section{References}

[1] C.T. Sun, Y.P. Lu, Vibration Damping of Structural
Elements, Prentice Hall, University of Michigan, 1995.

[2] J.E. Shigley, L.D. Mitchell, Mechanical Engineering Design, Mc Graw-Hill Book Company, New York, 1983.

[3] J. Hutchison, Shear coefficients for Timoshenko beam theory, Journal of Applied Mechanics 68 (1) (2000) 87-92.

[4] S.N. Patnaik, D.A. Hopkins, Strength of Materials: A New Unified Theory for the 21st Century, Elsevier, 2004.

[5] RDM Version $6.17 \quad$ [Online], http://iut.univ-lemans.fr/ydlogi/rdm_version_6.html.

[6] B.J. Lazan, Damping properties of composite material and materials, Applied Mechanics Reviews 15 (1962) 81-88.

[7] J. Neuringer, I. Elishakoff, Interesting instructional problems in column buckling for the strength of materials and mechanics of solids courses, Int. J. Engng Ed 14 (3) (1998) 204-216.

[8] H. Chandler, Cross Reference to Steels, Heat Treater's Guide: Practices and Procedures for Irons and Steels, 2nd ed., ASME International, 1995.

[9] J. Outinen, P. Mäkeläinen, Mechanical properties of structural steel at elevated temperatures and effective cooling down, in: 2nd International Workshop of Structures in Fire, Christchurch, Mar. 2002.

[10] C. Dolling, Material Selection, BCSA, Jan. 2006.

[11] Ivo Dlouhy, Transferability of Fracture Mechanical Characteristics, NATO Science Series II, Kluwer Academic Publishers, The Netherlands, 2002.

[12] R.C. Hibbeler, Engineering Mechanics: Statics, 10th ed., Pearson Prentice Hall, Upper Saddle River, New Jersey, 2004.

[13] The Steel Construction Institute, Steel Bridge Group: Guidance Notes on Best Practice in Steel Bridge, 2000. 